\title{
A pesquisa na área econômica sobre meio ambiente no Brasil: um estudo sobre a produção dos Programas de Pós-graduação Stricto Sensu da área de Economia de 2007 a 2012
}

Research in the economic area of the environment in Brazil: a study on the production of Graduate Programs Stricto Sensu Economic area from 2007 to 2012

\section{La investigación en el área económica del medio ambiente en Brasil: un estudio sobre la producción de los Programas de Postgrado Stricto Sensu del área Económica de 2007 a 2012}

Recherche dans le domaine de économie sur l'environnement au Brésil : une étude sur la production de programmes d'études supérieures Stricto Sensu la zone économique de 2007 à 2012

\author{
Valdineia Ribeiro de Oliveira* \\ (valdineia.r@ig.com.br) \\ Valdir Fernandes** \\ (valdir.fernandes@icloud.com) \\ Christian Luiz da Silva** \\ (christianlsilva76@gmail.com)
}

\begin{abstract}
Resumo: Este artigo tem por objetivo compreender como as questões ambientais vêm sendo incorporadas pela Área de Ciências Econômicas, no contexto dos Programas de Pós-Graduação Stricto Sensu da CAPES. Os resultados dão conta de que as pesquisas relacionadas às questões ambientais dentro dos programas de Pós-Graduação em Economia ainda são incipientes. Destaca-se o fato de que há uma pouca relação entre a ciência econômica e os problemas ambientais na pós-graduação brasileira, pois há o predomínio de temas relacionados à economia aplicada. Palavras-chave: Economia. Meio Ambiente. Pós-Graduação Stricto Senso no Brasil.

Abstract: This article aims to understand how environmental issues are being incorporated by the Economics Area, in the context of Graduate Stricto Sensu Programs CAPES. Results realize that research related to environmental issues within the Economy in the Graduate programs is still incipient. Noteworthy is the fact that there is little relationship between economics and environmental problems in the Brazilian post- graduation, as there is a predominance of topics related to applied economics.

Key words: Economics. Environmental. Graduate Programs Stricto Sensu in Brazil.

Résumé: Cet article vise à comprendre comment les questions environnementales sont incorporées par la zone Economics, dans le cadre des programmes d'études supérieures Stricto Sensu CAPES. Résultats rendent compte que la recherche liée aux questions environnementales au sein de l'économie dans les programmes d'études supérieures sont encore naissante. Remarquable est le fait qu'il ya peu de relation entre l'économie et les problèmes environnementaux dans la post-graduation brésilienne, comme il ya une prédominance des sujets liés à l'économie appliquée. Mots-clés: Economics. Environnementales. Programmes D'études Supérieures Stricto Sensu Brésil.

Resumen: Este artículo tiene como objetivo entender cómo los problemas del medio ambiente están siendo incorporados por el Área de Economía, en el contexto de los Programas de Postgrado en sentido estricto CAPES . Resultados dan cuenta de que la investigación relacionada con temas ambientales dentro de la economía en los programas de posgrado son aún incipientes. Es de destacar el hecho de que hay poca relación entre la economía y los problemas ambientales en el postgrado de Brasil, ya que hay un predominio de temas relacionados con la economía aplicada. Palabras clave: Economía. Medio Ambiente. Programas de Postgrado Stricto Sensu en Brasil.
\end{abstract}

\section{Introdução}

A economia, como ciência, estrutura-se em uma proposição metodológica positivista no século XVIII a partir de um contexto de revolução industrial e de reorganização dos fatores de produção e do consumo. Os propósitos dessa ciência fundamentaram-se em tratar a relação entre recursos escassos e necessidades ilimitadas a partir da organização

\footnotetext{
* Centro Universitário Franciscano do Paraná (UNIFAE), Curitiba, Paraná, Brasil.

**Universidade Tecnológica Federal do Paraná, Curitiba, Paraná, Brasil.
} 
e racionalização desses recursos para o atendimento de necessidades, criadas pelo mercado ou naturais para a sobrevivência. A visão propositiva trata dos recursos mais escassos à época, o que direciona a literatura clássica para a relação do trabalho, considerando este o principal fator atribuidor do valor de um produto.

Entretanto a própria tecnologia e (r)evolução da indústria tornou esse fator menos crucial para o processo de desenvolvimento de novos produtos ou serviços, associado ao crescimento vertiginoso da demanda, que ampliou o recurso trabalho e, ao mesmo tempo, viabilizou novas escalas de produção para o atendimento da crescente demanda. Essa relação criou um ciclo virtuoso de crescimento estagnado por movimentos anticíclicos do próprio sistema econômico, que trazia novas incógnitas para essa área de pesquisa.

A crise de 1929 foi marcante para uma nova preocupação e função do papel do Estado, reforçado após a Segunda Guerra Mundial, como agente organizador desses fatores de produção em nível macro e agente promotor ou regulador, dependendo da própria função do Estão no contexto histórico, do processo de intervenção para minimizar os ciclos econômicos.

Entretanto os movimentos sociais pós Segunda Guerra Mundial, que buscavam repensar a relação entre Estado e sociedade e norteavam a revisão dos limites do crescimento econômico, em um novo embate dentro e fora desse campo teórico. Com a primeira grande crise do Petróleo nessa mesma década de 1970 e com a iminência de uma crise energética, se começou a pensar em meio ambiente neste campo teórico. As questões relativas à natureza reforçaram-se como limitadores desse processo de crescimento e o dilema entre meio ambiente e crescimento econômico tomou um novo patamar de discussão.

Entretanto a questão do meio ambiente teve mais dificuldades de orientar essa discussão, seja pela própria racionalização do valor dos recursos ambientais que ainda não formalizam mercados, espaço próprio da discussão de qualquer atividade econômica, seja pelos frutos mais prospectivos que assertivos na contribuição dessa ciência para a sociedade. Mas não há como se furtar desse recurso que efetivamente demonstra a sua escassez e relação com as transações econômicas, o que denota um campo da economia que desenvolve abordagens diferenciadas, como a economia ambiental, que tenta valorizar os bens ou serviços ambientais, ou a economia ecológica, que visa compreender o processo entrópico entre relação econômica e o meio ambiente.

Considerando o sistema de pós-graduação do Brasil como fomentador da pesquisa e do norte teórico tratado por pesquisadores e novos doutores, questiona-se: no quantum de conhecimento produzido pelas pesquisas da área de Ciências Econômicas, como vêm sendo incorporadas as questões ambientais nas pesquisas no contexto dos programas de Pós-Graduação da Área de Ciências Econômicas da CAPES?

Dessa forma, o objetivo deste artigo é apresentar resultado de análise relativa às pesquisas recentes desenvolvidas pela área econômica sobre o meio ambiente, a partir da caracterização dos programas e dos temas predominantes da Pós-Graduação das Ciências Econômicas no Brasil.

Caracteriza-se como exploratória, segundo as definições de Quivy e Campenhoudt (2008), na medida em que sistematiza uma abordagem, um campo ou uma perspectiva ainda pouco abordados. Pesquisa junto aos Programas de Pós-Graduação da Área de Ciências Econômicas da Capes, com conceito maior ou igual a 3 no último triênio pela CAPES. Busca compreender as características dos programas de Pós-Graduação das Ciências Econômicas, quanto às áreas de concentração e linhas de pesquisa e trabalhos de conclusão. Os dados foram coletados diretamente nos websites da CAPES e dos Programas de Pós-Graduação. A análise se deu a partir de segregação das informações em tabelas, considerando temas das pesquisas. O pressuposto é que o tema não é predominante na discussão desse campo de pesquisa, apesar de ser presente como uma das áreas de interesse.

O artigo está organizado em quatro sessões, além desta introdução. A sessão segunda trata da relação entre economia e meio ambiente no campo teórico, com intuito de mostrar a evolução desse campo de discussão. A sessão seguinte trata a questão da pósgraduação no Brasil em economia. A quarta sessão apresenta os resultados da pesquisa 
e as discussões e, por fim, as conclusões da pesquisa.

\section{Economia e meio ambiente: aproximações em um campo teórico}

O período que antecede aos fundamentos do sistema capitalista foi predominado pelo Mercantilismo a partir da intensificação das relações comerciais utilizando-se de metais para a troca de bens. Pode ser considerado um período de nacionalismo, pois objetiva o enriquecimento do país por meio do acúmulo de metais preciosos, buscando resultados favoráveis no balanço comercial do país (BELL, 1976).

Ao contrário do pensamento mercantilista, baseado na supremacia do poder dos Estados, nasce o pensamento fisiocrata, no qual a riqueza não se encontra no superávit de transações comerciais, mas sim, no poder da natureza. Bell (1976, p. 123-124) expõe que a ordem natural da natureza poderia ser aplicada à relação que se tem entre o Estado, a indústria e o comércio, quando a produção e a distribuição deveriam ser realizadas de acordo com as leis fixas da natureza, sem interferência das restrições governamentais. Nesse pensamento, entre outros autores, destaca François Quesnay (1694-1774), considerado o fundador da fisiocracia, que defende a Lei do laissez faire, laissez passer, característica do liberalismo econômico.

Com Adam Smith, Thomas Malthus, John Stuart Mill e David Ricardo tem-se a ascensão do pensamento econômico clássico. Smith (1996, p.81) explora a divisão do trabalho, o modo como surge o uso do dinheiro nas relações comerciais, e suas inversões em novas mercadorias; procura caracterizar as relações de troca e faz a análise do valor, concluindo que o trabalho é a medida real do valor intercambiável de todas as mercadorias. Analisa também os salários, a origem da renda da terra, os lucros do capital. Assim, intensifica-se o pensamento liberal de economia autorregulada, e a riqueza das nações deixa de ser obtida apenas pela natureza e passa a ser obtida pela terra, capital e trabalho, predominando o laissez faire para a realização do comércio internacional.

Em 1798, Thomas Robert Malthus lançou seu Ensaio Sobre a População, a primeira preocupação com a população. O contexto em que se passa essa obra é o da Revolução Industrial. Malthus (1996, p. 6-7) observa o setor agrícola incapaz de produzir alimentos para toda a população, e, com as fábricas nas cidades, os trabalhadores migraram para as cidades, reduzindo salários reais e conduzindo à rápida acumulação de capitais na economia. Malthus considerou que todo homem estava destinado à pobreza, já que a população cresceria à taxa superior à taxa de produção de alimentos. Malthus concluiu que a população, se não controlada, cresceria em progressão geométrica, dobrando a cada 25 anos, enquanto isso a produção de alimentos, em seu estudo específico de análise da Grã-Bretanha, poderia ser aumentada a cada 25 anos, por uma quantidade de subsistência igual à que ela atualmente produzia, crescendo, dessa maneira, em progressão aritmética, o que conduziria a uma crise de falta de alimentos para manter a população. Esses cálculos não foram reais em função do progresso técnico e das novas tecnologias, que possibilitaram maior produção de alimentos, tais como adubos químicos, grãos híbridos, novas técnicas de cultivo, entre outros. Esta foi uma primeira aproximação da relação entre os recursos naturais como um fato efetivamente escasso e de valor, priorizando a terra como crucial para delineação da produção por conta da sua finitude.

A Revolução Industrial foi estratégica para a ascensão do capitalismo, entretanto as críticas a esse sistema foram rigorosas. Karl Marx, Weblen, Hobson, entre outros, criticaram o sistema. Para Marx (1996), o ponto de partida do capitalismo é a disponibilidade de uma mercadoria especial, a força de trabalho, que decorre de um longo processo de expropriação. Esse processo transfere para alguns a posse dos meios de produção impondo à grande maioria a condição de vendedor da força de trabalho, originando, assim, o conceito de Mais-Valia. Referindo-se a MaisValia, Marx critica esse modo de produção essencialmente porque é o valor do trabalho não pago ao trabalhador, levando à exploração exercida pelos capitalistas sobre seus assalariados e conduzindo à luta de classes entre a burguesia (os capitalistas donos dos meios de produção) e os operários.

O pensamento marginalista surge com Vilfredo Pareto, Stanley Jevons, Menger, 
Léon Walras, entre outros, que criticam o pensamento da economia clássica. Pensam a distribuição e a teoria do valor pela análise da procura e explicam o valor pela teoria da utilidade marginal. Jevons (1996, p. 136) diz que "enquanto o tão citado valor de uso de Adam Smith é a utilidade total de um bem para nós, o valor de troca é definido pela utilidade final, o desejo remanescente que nós ou outros temos de possuir mais". Permanece, portanto, a questão do trabalho nas discussões de valor. Para Menger, o valor surge como um resultado da relação entre a necessidade humana e os bens econômicos disponíveis capazes de satisfazer essa necessidade (BELL, 1976, p. 371). Para Walras, a utilidade marginal conduz ao equilíbrio geral, apresentando os princípios da economia de concorrência perfeita. Com Walras e Pareto, surge a utilização da matemática como técnica de análise econômica, ainda que ressaltando que a economia sempre estaria interessada nos problemas como o homem utiliza fontes escassas para a satisfação de suas necessidades.

Com Alfred Marshall, ascende a corrente teórica neoclássica, em 1890, com a publicação de Principles of Economics. Para Marshall (1996, p. 6), a "Economia com suas análises e leis não era um corpo de dogmas imutáveis e universais, e de verdade concreta, mas uma máquina para a descoberta da verdade concreta". Marshall (1996, p. 77) diz que "Economia Política ou Economia, é um estudo da Humanidade nas atividades correntes da vida; examina a ação individual e social em seus aspectos mais estreitamente ligados à obtenção e ao uso dos elementos materiais do bem-estar". Por isso, afirma que a economia estuda a riqueza, mas também estuda o homem; além disso, ressalta que existe uma relação intrínseca entre o econômico e a religião, que sempre teve influência acentuada nas relações econômicas.

Com a Revolução Industrial, e a grande massa da população nas cidades, surgem as populações extremamente pobres. Marshall chama a atenção que, nessas grandes cidades, onde se busca a riqueza e o trabalho, pouco tempo é dispensado à amizade e aos momentos para a união em família, nem mesmo a religião consegue alcançá-los, ou seja, tem-se trabalho, mas não se tem o bemestar. Assim, Marshall (1996, p. 364) afirma que para amenizar a pobreza, ultrapassam-se os recursos materiais do povo e os obrigam a exigir demasiado do solo com equipamento imperfeito e, assim, a provocar a ação enérgica da lei do rendimento decrescente a respeito dos produtos primários, sem ter o poder de reduzir os seus efeitos. "Tendo assim começado em condições de pobreza, um crescimento da população pode chegar às consequências tão frequentes de enfraquecimento do caráter que incapacita um povo a desenvolver uma indústria altamente organizada".

Com isso, desde os finais do século XIX, a preocupação com a escassez de recursos naturais delineia aspectos relevantes e inquietos para a discussão a luz da ciência econômica. Andrade (2013) retrata essa discussão ao afirmar sobre a insustentável relação entre a trajetória do sistema econômico e do relacionamento humano com o natural. Entretanto o autor reforça que a inadequação do instrumental neoclássico para tratar a questão ambiental se resume em três pontos:

mainstream econômico não reconhecer a problemática natural do capital natural enquanto obstáculo para o contínuo crescimento do sistema econômico [...] em segundo lugar, sua base de inspiração mecanicista sugere que todos os fenômenos são reversíveis e que não há a possibilidade de perdas irreparáveis [...] por último, o mainstream neoclássico é profundamente falho em desconhecer dos nexos entre o sistema econômico e sua base ecológica". (ANDRADE, 2013, p. 17).

O Keynesianismo surge com John Maynard Keynes em sua obra A Teoria Geral do Emprego, do Juro e da Moeda, e também com Michail Kalecki, o principal motivo da ascensão desse pensamento, é a Crise de 1929, conhecida como a Grande Depressão. Os postulados da economia clássica foram insuficientes para explicar essa crise. Nesse momento, Keynes tentou participar da reconstrução de um novo liberalismo, onde participou do Nation and A theneum, um seminário influente com objetivo de influenciar a posição do Partido Liberal.

No final dos anos 1920 e início dos anos 1930, Keynes começou a esboçar suas primeiras ideias quanto a questões polêmicas relacionadas ao desemprego avassalador do contexto e o impacto das obras públicas. Buscando a razão desse desemprego, que 
penalizava toda a sociedade, concluiu que eram oriundos de desajustes entre poupança (S) e investimento (I). Ou seja, para gerar poupança, precisa-se incentivar o consumo, gerando poupança interna, e consequentemente investimentos, que proporcionarão mais empregos, aumentando a demanda agregada e conduzindo a sociedade a sair da crise e a obter mais bem-estar.

A questão do bem-estar se fortalece nesse contexto, e a discussão sobre ação coletiva, por meio do Estado, é fonte de pesquisa e amadurecimento do campo teórico da economia. Nessa discussão, vinculam-se as ações coletivas para correção de falhas de mercado, o que associa alguns serviços ambientais aos bens públicos, de características não rivais e não exclusivos, como ar e água (ROMEIRO, 2003).

Diante de um contexto movimentos ambientalistas e sociais, frente ao forte crescimento econômico pós II Guerra Mundial, a partir de 1960, e da escassez do petróleo, na década de 1970, diferentes correntes de teóricos econômicos interpretavam essa relação insustentável entre o sistema econômico e a relação entre homem e meio ambiente. Alguns teorizavam sobre o crescimento, independentemente da existência de restrições naturais, como Robert Solow (1974) e Joseph Stiglitz (1974). Outros reforçavam a necessidade de compreensão dessa dinâmica e interação do recurso natural no meio econômico, como Baumol e Oates (1971). Alguns mais restritivos com relação ao crescimento, como Georgescu-Roegen (1971), Ward e Dubos (1972).

A controvérsia não permitiu enfrentar o problema da relação entre o sistema econômico e os sistemas naturais. A teoria da valoração econômica tenta aproximar o problema relativo ao meio ambiente ao mainstream econômico (MOTTA, 2007; MOTA, 2006). A clareza da importância da relação entre economia e meio ambiente é natural, porém pouco explorada, como cita Hackett (2006), ao explicar que os economistas aprendem pouco sobre o meio ambiente e os estudiosos das ciências ambientais aprendem pouco sobre economia, mas os sistemas interagem em muitos caminhos. Há, portanto, segundo Lisboa (2000, p. 17), uma "desconexão entre a ciência econômica e as demais ciências do social", o que significa dizer que há também uma desconexão entre a ciência econômica e os problemas da sociedade que não aqueles de economia aplicada, ou seja, um pensamento simplista acerca do funcionamento e da dinâmica social que se reduz ao econômico.

Como definiu Weber $(1996 ; 1999)$ e retomado pela Escola de Frankfurt (HORKHEIMER, 2002), o sistema econômico capitalista é dotado de um espírito, a racionalidade instrumental, que possibilitou o domínio da técnica e sua constante evolução e aperfeiçoamento e, por isso, se tornou o sistema hegemônico na sociedade contemporânea. Entretanto as bases desse sistema, segundo Polanyi (1994), são o capital natural e o capital criativo. Interpretando Polanyi (1994), podese afirmar que economia deve aplicar o seu princípio de melhor alocação dos recursos disponíveis, que, no atual contexto, significa trabalhar com a iminência da exaustão dos recursos naturais e o potencial de trabalho, por meio da criatividade que pode ser representada pelas novas formas de inovação. Nesse contexto, buscou-se compreender como os programas de pós-graduação stricto sensu no Brasil na área econômica tratam dessa temática por meio de suas pesquisas e linhas de pesquisa.

\section{Pós-graduação da área de Ciências Econômicas da CAPES}

A área de Economia possui atualmente, de acordo com o documento de área, 56 programas de pós-graduação com 79 cursos aprovados pela CAPES, sendo 42 mestrados acadêmicos, 23 mestrados/doutorados e 14 mestrados profissionais. Apresenta-se uma tendência de crescimento do mestrado profissional, pois se elevou de 4 programas no ano de 1999 para 14 em 2013 (CAPES, 2013, p. 1).

Quanto à distribuição geográfica dos programas da área de Economia quase a metade (27) encontra-se na região Sudeste, que, com exceção do Espírito Santo, em todos os demais estados dessa região têm cursos de mestrado profissional, mestrado acadêmico e mestrado/doutorado. Observando o mesmo nos estados do Paraná e do Rio Grande do Sul, na região do Sul, onde apenas Santa Catarina conta com um curso de mestrado/doutorado. Já na região Nordeste, predominam os 
mestrados acadêmicos (6), e os cursos de mestrado/doutorado estão situados nos estados de Ceará, Paraíba e Pernambuco. Os cursos da Região Centro Oeste de mestrado/doutorado (2) encontram-se no Distrito Federal, e na região Norte apenas no Pará a área de economia tem um curso de mestrado acadêmico.

Com relação à formação de recursos humanos, a área de Economia titulou 1.243 mestres acadêmicos no triênio 2007 a 2009, 884 mestres profissionais e 346 doutores. Nos anos de 2010 e 2011, os números ficaram em 888 novos mestres acadêmicos, 728 novos mestres profissionais e 281 novos doutores. $\mathrm{O}$ ano de 2012, que fecha o triênio, ainda tinha informações disponíveis na conclusão desta pesquisa.

O Documento de Área da CAPES (2013) ressalta que, nos últimos anos, a produção científica dos programas de pós-graduação em Economia vem apresentando um crescimento expressivo, com significativo aumento na publicação em periódicos internacionais de qualidade, fruto da mobilização de muitos pesquisadores/programas em busca da excelência. Nessa perspectiva, a avaliação da área tem mostrado uma maior internacionalização dos programas, com reflexo em suas notas. Dessa forma, no último triênio (ou no momento do credenciamento) para os programas novos, a distribuição atual encontra-se com 11 programas com nota 3 e 9 programas com nota 4, para o mestrado acadêmico, de acordo com gráfico 6. Para o mestrado/ doutorado, têm-se 5 programas com nota 4; 8 programas com notas 5,3 programas com notas 6 e 2 programas com notas 7 , conforme apresentado no gráfico 7 . O gráfico 7 mostra uma evolução positiva, com perspectivas de melhoria no decorrer dos próximos anos.

A interdisciplinaridade em Economia foi discutida recentemente entre os coordenadores da pós-graduação no segundo seminário de acompanhamento da área do triênio, no primeiro trimestre de 2013. Segundo o Documento de Área (CAPES 2013, p. 6). chegou-se a um consenso, de que Área de Economia pode contribuir para o avanço da perspectiva interdisciplinar, uma vez que é uma ciência em que há interseções com muitas outras ciências. Citam-se exemplos de interdisciplinaridade com áreas como administração, ciência política e relações in- ternacionais, direito, educação, engenharia, história, medicina, planejamento urbano e regional, demografia, psicologia, sociologia, serviço social, zootecnia, ciências agrárias, e entre tantas outras, e nas ciências ambientais, relação discutida nesta pesquisa.

Apesar dessa conclusão, os coordenadores identificaram uma grande dificuldade em traçar o limite do que é estritamente da área de economia. Mesmo com essa dificuldade, os coordenadores de programas de pósgraduação, em sua maioria, reconheceram a relevância de não se penalizar cursos com viés de economia aplicada, que trabalham de maneira mais evidente na fronteira da economia com demais áreas do conhecimento. $\mathrm{O}$ que tem se observado, também, é o constante intercâmbio de alunos, com recebimento de alunos de outras áreas e reconhecimento de disciplinas feitas por alunos de economia em programas de pós-graduação de outras áreas (CAPES, 2013, p. 6).

Tanto o mestrado acadêmico, quanto o doutorado e o mestrado profissional, têm no documento de área, ser fundamental que o programa tenha em seu eixo central disciplinas associadas a teoria econômica e métodos quantitativos, quais sejam: Macroeconomia, Microeconomia e Métodos Quantitativos, tendo as demais disciplinas que estabelecer relações com as linhas de pesquisa do programa. Daí a relativa dificuldade de se ter pesquisas relacionadas ao meio ambiente dentro do escopo dos programas de Pós-Graduação de Economia (CAPES, 2013, p. 7). Assim, a lista das disciplinas precisa ser apresentada em conjunto com as ementas, que devem mostrar a bibliografia compatível com o programa com objetivos e estruturas próximas aos do programa em análise.

Com relação ao corpo docente, este precisa ser integrado, de maneira equilibra$\mathrm{da}$, por doutores, por profissionais e técnicos com experiência em pesquisa aplicada ao desenvolvimento e à inovação, de acordo com a Portaria Normativa MEC $n^{\circ} 17$ de 28 de dezembro de 2009. O corpo docente deve ser bem qualificado com experiências relevantes, execução de projetos de pesquisa aprovados por agências de pesquisa e/ou empresas, devendo comprovar a carga horária docente e condições de trabalho compatíveis com as necessidades do curso. Também para o 
mestrado profissional, o número mínimo de docentes permanentes, na Área de Economia, deve ser sete para os cursos de mestrado, e o percentual de docentes permanentes com atuação como permanente em outro Programa de Pós-Graduação não pode ultrapassar a $40 \%$. Além disso, o currículo dos professores deve estar relacionado à área do mestrado profissional e deve haver experiências prévias de trabalhos compartilhados entre os membros do corpo docente CAPES (2013, p. 15).

Por ser um mestrado profissional aceitar-se-á uma maior participação de professores externos à IES. Entretanto essa participação não pode caracterizar dependência, seja em termos de produção, seja em termos das disciplinas básicas do programa, pois as Portarias da CAPES n $n^{\circ} 1$ e $n^{\circ} 2 / 2012$ devem ser respeitadas. Também se faz necessário estabelecer explicitamente a experiência prévia com orientação do corpo docente.

Sobre as avaliações da área, parte-se das Fichas de Avaliação, que fornecem informações sobre os critérios a serem adotados pela Comissão da Área de Economia na avaliação dos Programas de Pós-Graduação acadêmicos e profissionais no triênio de 2010-2012. A avaliação tanto dos cursos acadêmicos quanto dos cursos profissionais foi feita com base em cinco quesitos padronizados para a avaliação de todas as áreas de conhecimento, segundo a CAPES (2013, p. 16), a saber:

Tabela 1 - Requisitos para Avaliação da Pós-Graduação

\begin{tabular}{l|c|c}
\multicolumn{1}{c|}{ Quesito } & $\begin{array}{c}\text { Peso Cursos Acadêmicos } \\
(\mathbf{\%})\end{array}$ & $\begin{array}{c}\text { Peso Mestrado Profissional } \\
(\mathbf{\%})\end{array}$ \\
\hline 1. Proposta do Programa & 0 & 0 \\
\hline 2. Corpo Docente & 20 & 20 \\
\hline 3. Corpo Discente, Teses e Dissertações & 35 & 30 \\
\hline 4. Produção intelectual & 35 & 30 \\
\hline 5. Inserção Social e Relevância & 10 & 20 \\
\hline
\end{tabular}

Fonte: CAPES, 2013, p. 16.

A proposta do programa possui peso zero porque trata de um quesito que fornece indicadores qualitativos para a atribuição da nota final, e também, atua como uma trava, uma vez que, se não for considerado com qualidade informativa suficiente, pode inviabilizar a proposta de programa.

Com relação ao Corpo Docente, este permite avaliar a competência e maturidade científica para desenvolver as atividades de ensino, pesquisa e orientação do programa, constituindo-se em quesito fundamental na avaliação do bom desempenho do Programa. Recebeu ponderação menor que corpo discente e teses e dissertações e produção intelectual porque é considerado um requisito com capacidade reduzida relativa de discriminação entre os programas, visto a organização e estruturação atuais da maioria deles (CAPES, 2013, p. 17).

Corpo Discente, Teses e Dissertações e Produção Intelectual são avaliados como pontos mais relevantes, pois priorizam os produtos e não os processos, representando os resultados do programa em termos de novos pesquisadores formados e titulados e da produção intelectual dos mesmos associados à produção docente (CAPES, 2013, p. 17).

O quesito Inserção Social/Internacional analisa a atuação do programa no contexto regional, nacional e internacional, e considera o impacto científico, tecnológico, econômico e educacional, bem como o envolvimento em ações de integração social e de solidariedade (CAPES, 2013, p. 17).

\section{Resultados e discussões}

A Pós-Graduação da área de Ciências Econômicas da CAPES (2013) encontra-se inserida dentro da denominada Grande Área de Ciências Sociais Aplicadas. Analisando a Grande Área de Ciências Sociais Aplicadas, verifica-se a Área de Economia, que atualmente possui 80 cursos de Pós-Graduação que compõem 57 programas. Representa, dessa forma, $12 \%$ tanto de programas, quanto de cursos, em relação ao total da Grande Área 
de Ciências Sociais Aplicadas. Constitui-se na terceira mais relevante área das Ciências Sociais Aplicadas, pois Administração, Contábeis e Turismo somam $26 \%$, e Direito $18 \%$. A importância da economia na Pós-Graduação é fundamental para o desenvolvimento do país, mas há concentração em alguns temas de economia aplicada.

Tabela 2 - Programas e cursos de pós-graduação por área de avaliação das Ciências Sociais Aplicadas

\begin{tabular}{|c|c|c|c|c|c|c|c|c|c|}
\hline \multirow[t]{2}{*}{ ÁREA (Área de avaliação) } & \multicolumn{5}{|c|}{$\begin{array}{l}\text { Programas e Cursos de } \\
\text { Pós-Graduação }\end{array}$} & \multicolumn{4}{|c|}{$\begin{array}{l}\text { Totais de Cursos de } \\
\text { Pós-Graduação }\end{array}$} \\
\hline & Total & $\mathbf{M}$ & D & $\mathbf{F}$ & M/D & Total & $\mathbf{M}$ & $\mathrm{D}$ & $\mathbf{F}$ \\
\hline $\begin{array}{l}\text { Administração (Administração, Ciências } \\
\text { Contábeis e Turismo) }\end{array}$ & 132 & 37 & 2 & 55 & 38 & 170 & 75 & 40 & 55 \\
\hline $\begin{array}{l}\text { Arquitetura e Urbanismo (Arquitetura e } \\
\text { Urbanismo) }\end{array}$ & 33 & 14 & 0 & 4 & 15 & 48 & 29 & 15 & 4 \\
\hline $\begin{array}{l}\text { Ciência da Informação (Ciências Sociais } \\
\text { Aplicadas I) }\end{array}$ & 15 & 3 & 0 & 4 & 8 & 23 & 11 & 8 & 4 \\
\hline Comunicação (Ciências Sociais Aplicadas I) & 44 & 23 & 0 & 1 & 20 & 64 & 43 & 20 & 1 \\
\hline Demografia (PUReDemografia) & 4 & 2 & 0 & 0 & 2 & 6 & 4 & 2 & 0 \\
\hline Desenho Industrial (Arquitetura e Urbanismo) & 17 & 6 & 0 & 3 & 8 & 25 & 14 & 8 & 3 \\
\hline Direito (Direito) & 84 & 53 & 0 & 1 & 30 & 114 & 83 & 30 & 1 \\
\hline Economia (Economia) & 57 & 19 & 0 & 15 & 23 & 80 & 42 & 23 & 15 \\
\hline Economia Doméstica ( Serviço Social ) & 1 & 1 & 0 & 0 & 0 & 1 & 1 & 0 & 0 \\
\hline Museologia (Ciências Sociais Aplicadas I) & 3 & 2 & 0 & 0 & 1 & 4 & 3 & 1 & 0 \\
\hline Planejamento Urbano e Regional (PUReD) & 32 & 14 & 0 & 8 & 10 & 42 & 24 & 10 & 8 \\
\hline Serviço Social (Serviço Social) & 32 & 18 & 0 & 0 & 14 & 46 & 32 & 14 & 0 \\
\hline $\begin{array}{l}\text { Turismo (Administração, Ciências Contábeis e } \\
\text { Turismo) }\end{array}$ & 7 & 4 & 0 & 2 & 1 & 8 & 5 & 1 & 2 \\
\hline Brasil & 461 & 196 & 2 & 93 & 170 & 631 & 366 & 172 & 93 \\
\hline
\end{tabular}

Fonte: CAPES (2013).

A análise da distribuição geográfica dos programas de Pós-Graduação em Economia é relevante para se buscar a influência das necessidades de desenvolvimento regional do país. Percebe-se, de acordo com a tabela 3 , que há grande concentração da pesquisa de Economia da região sudeste [São Paulo, Rio de Janeiro, Minas Gerais e Espírito Santo], onde se encontram grandes centros de excelência em estudos dessa área [com melhores conceitos], representando $47 \%$ dos programas de pós da área. Essas universidades centram suas pesquisas em Teoria Econômica e Economia Aplicada, que mais adiante serão mais bem analisadas. A segunda maior representatividade dessa área encontra-se na região nordeste do país, com $23 \%$ dos programas em suas universidades, seguida do sul com $19 \%$, centro-oeste com $9 \%$, e norte com apenas $2 \%$.
Tabela 3 - Distribuição de Programas em Economia por Região

\begin{tabular}{lcc}
\hline Regiões & Quantidade & $\%$ \\
\hline Sul & 11 & 19 \\
Sudeste & 27 & 47 \\
Centro-Oeste & 5 & 9 \\
Nordeste & 13 & 23 \\
Norte & 1 & 2 \\
\hline Brasil & 57 & 100 \\
\hline
\end{tabular}

Fonte: CAPES (2013)

No que se refere à qualidade, a CAPES possui uma escala de conceitos na análise de cada curso de Pós-Graduação, conforme visualizam-se na tabela 4 , os conceitos referentes ao mestrado acadêmico, mestrado profissional e doutorado, concluindo que os conceitos 3 e 4 ainda são predominantes na área, o que indica necessidade de se buscar melhores resultados no futuro. 
Tabela 4 - Distribuição de Cursos de Pós-Graduação de Economia por Conceito/Nota

\begin{tabular}{lcccccc}
\hline Cursos / Conceitos 2012 & $\mathbf{3}$ & $\mathbf{4}$ & $\mathbf{5}$ & $\mathbf{6}$ & $\mathbf{7}$ & Total \\
\hline Doutorado & - & 10 & 8 & 3 & 2 & 23 \\
Mestrado Acadêmico & 15 & 14 & 8 & 3 & 2 & 42 \\
Mestrado Profissional & 5 & 6 & 4 & - & - & 15 \\
\hline Total & 20 & 30 & 20 & 6 & 4 & 80
\end{tabular}

Fonte: CAPES (2013)

As principais linhas de pesquisa presentes nos programas de pós-graduação da área de economia são evidenciadas na tabela 5. Observa-se que, dentre as pesquisas no âmbito da Área de Economia, apenas 2\% voltam-se a estudar sobre o meio ambiente, a melhor alocação dos recursos naturais e gestão do meio ambiente num todo.

Tabela 5 - Principais Linhas de Pesquisa - Pós-Graduação em Ciências Econômicas

\begin{tabular}{|c|c|c|c|c|c|}
\hline $\begin{array}{c}\text { Principais Linhas de Pesquisa - Pós-Graduação em } \\
\text { Ciências Econômicas }\end{array}$ & M Prof & M Acad & Dout. & Total & $\%$ \\
\hline $\begin{array}{l}\text { Economia Aplicada / Métodos Quantitativos / } \\
\text { Econometria / Macroeconomia / Monetária }\end{array}$ & 5 & 13 & 11 & 29 & $16 \%$ \\
\hline Teoria econômica / Política econômica & 1 & 9 & 8 & 18 & $10 \%$ \\
\hline $\begin{array}{l}\text { Desenvolvimento regional e urbano / Economia } \\
\text { Regional e Rural e Brasileira }\end{array}$ & 1 & 11 & 4 & 16 & $9 \%$ \\
\hline Desenvolvimento Econômico & 2 & 7 & 6 & 15 & $8 \%$ \\
\hline Economia Geral & 1 & 7 & 5 & 13 & $7 \%$ \\
\hline $\begin{array}{l}\text { Finanças / Finanças Públicas e Estado / Mercado } \\
\text { Financeiro }\end{array}$ & 6 & 3 & 3 & 12 & $7 \%$ \\
\hline $\begin{array}{l}\text { Economia das Empresas e Investimentos / } \\
\text { Controladoria }\end{array}$ & 7 & 4 & 1 & 12 & $7 \%$ \\
\hline Economia internacional / Comércio Internacional & 3 & 5 & 3 & 11 & $6 \%$ \\
\hline Economia do trabalho e Social & & 6 & 4 & 10 & $6 \%$ \\
\hline $\begin{array}{l}\text { História Econômica / instituições e desenvolvimento } \\
\text { econômico }\end{array}$ & & 5 & 5 & 10 & $6 \%$ \\
\hline Economia política / Política Social & 1 & 3 & 2 & 6 & $3 \%$ \\
\hline Economia Industrial e de Redes e Inovação & 1 & 2 & 2 & 5 & $3 \%$ \\
\hline Economia Agrícola & & 3 & 1 & 4 & $2 \%$ \\
\hline $\begin{array}{l}\text { Economia do Meio Ambiente / Ec. Agrícola e dos Rec. } \\
\text { Naturais e Gestão Econ. do Meio Ambiente. }\end{array}$ & & 2 & 2 & 4 & $2 \%$ \\
\hline Economia do setor público & 1 & 1 & 2 & 4 & $2 \%$ \\
\hline Políticas Públicas & 1 & 1 & & 2 & $1 \%$ \\
\hline Políticas de Desenvolvimento & 1 & 1 & & 2 & $1 \%$ \\
\hline Agronegócio e Desenvolvimento Regional & 1 & 1 & & 2 & $1 \%$ \\
\hline Economia da mundialização e do desenvolvimento & 1 & & & 1 & $1 \%$ \\
\hline Economia das Organizações e Gestão Agroindustrial & & 1 & & 1 & $1 \%$ \\
\hline Gerenciamento de projetos & 1 & & & 1 & $1 \%$ \\
\hline Gestão e Economia da Saúde & 1 & & & 1 & $1 \%$ \\
\hline Regulação e competitividade & 1 & & & 1 & $1 \%$ \\
\hline Economia Digital e Comércio Eletrônico & 1 & & & 1 & $1 \%$ \\
\hline Total & 37 & 85 & 59 & 181 & $100 \%$ \\
\hline
\end{tabular}

Fonte: CAPES (2013) 
A análise subsequente identifica os principais temas das teses e dissertações dos discentes de economia. Para tanto, foi selecionada a quantidade de teses e dissertações de todos os programas de pós-graduação em economia avaliados pela CAPES. Para essa coleta de dados, foi considerado o último triênio avaliado, ou seja, os anos de 2007 a 2009. Nessa análise, é realizado um comparativo.
Em um primeiro momento, pelos principais temas que norteiam a pesquisa em economia, utilizou-se o critério de selecionar os principais temas propostos pelos programas e defendidos pelos pesquisadores, as principais linhas de pesquisa em questão no último triênio avaliado pela CAPES. Posteriormente, compara-se esse estudo com o percentual de pesquisa que a Economia realiza considerando as questões ambientais.

Tabela 6 - Teses e dissertações defendidas no período 2007-2009 referentes aos principais temas de Economia

\begin{tabular}{lcc}
\hline \multicolumn{1}{c}{ Principais temas / Linhas de Pesquisa } & Teses e Dissertações & $\%$ \\
\hline Economia Aplicada / Métodos Quantitativos / Econometria / & 495 & $28 \%$ \\
Macroeconomia / Monetária & 340 & $19 \%$ \\
Desenvolvimento Econômico & 165 & $9 \%$ \\
Economia das Empresas e Investimentos / Controladoria & 118 & $7 \%$ \\
Finanças / Finanças Públicas e Estado / Mercado Financeiro & 112 & $6 \%$ \\
Economia do trabalho e Política Social e Economia Política & 107 & $6 \%$ \\
Análise de Investimentos, Organizações & 106 & $6 \%$ \\
Economia Agrícola e Regional & 101 & $6 \%$ \\
Teoria econômica / Política econômica & 101 & $6 \%$ \\
Desenvolvimento regional e urbana / Economia Regional e Rural & & $4 \%$ \\
e Brasileira & 67 & $2 \%$ \\
Economia do Meio Ambiente / Ec. Agrícola e dos Rec. Naturais e & 27 & $1 \%$ \\
Gestão Econ. do Meio Ambiente & 11 & $100 \%$ \\
Economia internacional / Comércio Internacional & 1750 & \\
Regulação e competitividade & & \\
\hline Total & & \\
\hline
\end{tabular}

Fonte: CAPES (2013)

De acordo com a tabela 6, visualiza-se que os principais temas que preocupam a PósGraduação da área de economia são os de economia aplicada, com $28 \%$ do total do período analisado, sendo que as questões ambientais correspondem a apenas $4 \%$. Levando-se em consideração toda importância que essas questões representam para a sociedade atual, este é um percentual muito pequeno.

Uma outra conclusão referente às teses e dissertações é que, em alguns programas, existem linhas de pesquisas relacionadas às questões ambientais, ficando a critério dos discentes optarem por pesquisas nesse cam- po. O que acontece, entretanto, é a opção por outras linhas de pesquisas.

As tabelas que se seguem, tabelas 7, 8 e 9, mostram que existem algumas linhas de pesquisa dentro da área de economia que tratam de questões ambientais. Mas, mesmo quando o programa traz essa possibilidade, poucos discentes optam por fazer suas pesquisas de mestrado e doutorado nessa linha de pesquisa. Talvez o que falte seja incentivo por parte dos docentes a instigarem os discentes a pesquisarem sobre essas questões chave para a sociedade a partir do momento atual que exige tais preocupações. 
Tabela 7 - Total de teses e dissertações: comparativo entre Economia e Meio Ambiente período 2007-2009

\begin{tabular}{lccccc}
\hline \multicolumn{1}{c}{ Dissertações / Teses } & $\begin{array}{c}\text { Total } \\
\text { Economia }\end{array}$ & $\mathbf{0}$ & $\begin{array}{c}\text { Total Meio } \\
\text { Ambiente }\end{array}$ & $\mathbf{\%}$ & $\%$ \\
\hline Total de dissertações Mestrado Acadêmico & 940 & $54 \%$ & 35 & $52 \%$ & $4 \%$ \\
Total de dissertações Mestrado Profissional & 572 & $33 \%$ & 28 & $42 \%$ & $5 \%$ \\
Total de Teses & 238 & $14 \%$ & 4 & $6 \%$ & $2 \%$ \\
\hline
\end{tabular}

Fonte: CAPES (2013)

Tem-se que $54 \%$ de toda pesquisa em Economia provêm de dissertações de mestrado acadêmico; 33\% de dissertações, de mestrado profissional; e $14 \%$, de doutorados. Das pesquisas relacionadas com questões ambientais, tem-se $52 \%$ provenientes de dissertações de mestrado acadêmico; $42 \%$ de mestrado profissional; e $6 \%$ de doutorados. Ao comparar a quantidade de pesquisas relacionadas às questões ambientais com o restante das pesquisas em Economia, tem-se que, de todas as dissertações de mestrado acadêmico, apenas $4 \%$ inserem-se dentro de temas relacionados a questões ambientais; apenas 5\% com relação no mestrado profissional; e apenas $2 \%$ no doutorado.

Este resultado pode ser explicado pela tradição de formação presente nos CURRÍCULOS das Faculdades/Universidades, que seguem à própria tradição da ciência econômica, nos quais constata-se uma maioria centrada em estudos de modelos clássicos, ou marxistas, ou Keynesianos, que tradicionalmente excluem o meio ambiente da equação econômica e mantêm a desconexão dos demais problemas da sociedade. Nesse sentido, pode-se inferir que os campos de aplicação dos produtos gerados pelas pesquisas realizadas no contexto dos programas de pósgraduação da área de economia, voltam-se prioritariamente para: Modelos quantitativos de crescimento econômico; Estudos de taxa de juros, câmbio, e geração de emprego e renda; Comércio Internacional; Desenvolvimento Econômico em temas que abarcam o conceito de desenvolvimento como resultado de emprego e renda pela industrialização, e ainda não aplica o desenvolvimento em seu sentido de desenvolvimento sustentável com valoração econômica dos recursos naturais e dos impactos ambientais; Economia do trabalho; Economia empresarial, em função dos mestrados profissionais.

Do percentual reduzido de pesquisas que consideram questões ambientais destacam-se: energia, água, empregos verdes e crédito de carbono. Além desses resultados, foram feitas análises dos resumos dessas teses e dissertações por palavras chave, o que conduziu ao seguinte resultado, conforme tabela 8 .

Tabela 8 - Cômputo das dissertações e teses produzidas pelos programas da área de economia (período 2007-2009), em conformidade com temas ligados as questões ambientais

\begin{tabular}{c|l|c|c|c}
\hline $\mathbf{N}^{\mathbf{0}}$ & \multicolumn{1}{|c|}{ TEMAS DAS QUESTÕES AMBIENTAIS } & $\begin{array}{c}\text { Palavras-chave } \\
\text { (algumas) }\end{array}$ & Dissertações & Teses \\
\hline 01 & Economia verde / Empregos verdes & 3 & 2 & 3 \\
\hline 02 & Energia & 9 & 6 & 9 \\
\hline 03 & Cidades sustentáveis & 12 & 5 & 12 \\
\hline \multirow{2}{*}{04} & $\begin{array}{l}\text { Alimentos (segurança alimentar e Agricultura } \\
\text { Sustentável) }\end{array}$ & 4 & 2 & 4 \\
\hline 05 & Água & 5 & 1 & 5 \\
\hline 06 & Oceanos & 9 & 3 & 9 \\
\hline 07 & Desastres naturais (redução de riscos e resiliência) & 2 & - & 2 \\
\hline 08 & Outros temas & 3 & 1 & 3 \\
\hline \multirow{2}{*}{ Total } & - & 47 & 20 \\
\hline
\end{tabular}

Fonte: Os autores. Dados oriundos de dissertações de cursos avaliados pela CAPES (2013). 
De acordo com a tabela 8, percebe-se que, ao pesquisar por palavras-chave nas teses e dissertações dos programas de pósgraduação da área de Economia, encontrase alguma pesquisa relacionada à área de questões ambientais. Mas em comparação com cursos de outras áreas, ainda é pequeno em relação às possibilidades que se têm de pesquisa nessa área.

No que se refere à atuação dos docentes em pesquisas no âmbito dos programas de pós-graduação da Área de Economia, concluise que, assim como as linhas de pesquisa dos programas, também seus docentes estão trabalhando em sua maioria com ciências sociais aplicada e métodos quantitativos. A maioria, como se observa na tabela 9, está em Economia Geral, mas, ao visualizar o Curriculum Lattes de alguns desses docentes, também o que se encontra é formação dentro dessas linhas mais técnicas e quantitativas.

Tabela 9 - Corpo Docente da Área de Economia por Linha de Pesquisa (2007-2009)

\begin{tabular}{|c|c|c|c|c|c|c|}
\hline $\begin{array}{c}\text { Corpo Docente por Área de Atuação - } \\
\text { Pós-Graduação Economia }\end{array}$ & $\begin{array}{l}\text { Total } \\
2007\end{array}$ & $\%$ & $\begin{array}{l}\text { Total } \\
2008\end{array}$ & $\%$ & $\begin{array}{l}\text { Total } \\
2009 \\
\end{array}$ & $\%$ \\
\hline Economia Geral & 294 & $50 \%$ & 299 & $51 \%$ & 378 & $56 \%$ \\
\hline $\begin{array}{l}\text { Ciências Sociais Aplicadas / Matemática / } \\
\text { Engenharias/ Métodos Quantitativos / Estatística }\end{array}$ & 126 & $21 \%$ & 120 & $20 \%$ & 98 & $15 \%$ \\
\hline Economia agrária / Regional e Urbana & 42 & $7 \%$ & 40 & $7 \%$ & 38 & $6 \%$ \\
\hline Economia Internacional / Econ. Monetária e Fiscal & 14 & $2 \%$ & 15 & $3 \%$ & 13 & $2 \%$ \\
\hline Teoria Econômica & 17 & $3 \%$ & 19 & $3 \%$ & 14 & $2 \%$ \\
\hline Sociologia / Sociologia Rural & 5 & $1 \%$ & 5 & $1 \%$ & 8 & $1 \%$ \\
\hline Ciências Humanas & 11 & $2 \%$ & 16 & $3 \%$ & 16 & $2 \%$ \\
\hline Economia Industrial & 7 & $1 \%$ & 9 & $2 \%$ & 9 & $1 \%$ \\
\hline Administração & 8 & $1 \%$ & 9 & $2 \%$ & 9 & $1 \%$ \\
\hline Economia dos Recursos Naturais e Recursos Florestais & 6 & $1 \%$ & 7 & $1 \%$ & 11 & $2 \%$ \\
\hline História Econômica & 9 & $2 \%$ & 8 & $1 \%$ & 13 & $2 \%$ \\
\hline Arquitetura e Urbanismo e Demografia & 3 & $1 \%$ & 3 & $1 \%$ & 5 & $1 \%$ \\
\hline Ciência Política & 10 & $2 \%$ & 10 & $2 \%$ & 15 & $2 \%$ \\
\hline Economia do Desenvolvimento & 18 & $3 \%$ & 20 & $3 \%$ & 25 & $4 \%$ \\
\hline Mudança tecnológica & 4 & $1 \%$ & 3 & $1 \%$ & 6 & $1 \%$ \\
\hline Comunicação & 5 & $1 \%$ & 2 & $0 \%$ & 4 & $1 \%$ \\
\hline Inovação, Instituições e Competitividade & 4 & $1 \%$ & 2 & $0 \%$ & 3 & $0 \%$ \\
\hline Finanças Públicas Internas & 5 & $1 \%$ & 5 & $1 \%$ & 7 & $1 \%$ \\
\hline Total & 588 & $100 \%$ & 592 & $100 \%$ & 672 & $100 \%$ \\
\hline
\end{tabular}

Fonte: Os autores (2013). Dados oriundos do caderno de indicadores da CAPES (2013).

\section{Considerações finais}

O objetivo deste artigo foi apresentar resultados de pesquisa sobre as questões ambientais que vêm sendo incorporados pela Área de Ciências Econômicas, no contexto dos Programas de Pós-Graduação Stricto Sensu.

Dentre as principais inferências deste estudo, destaca-se o fato de que há uma desconexão entre a ciência econômica e os problemas ambientais, o que representa menos de $5 \%$ dos estudos da área. Há, em contrapartida, um predomínio de temas relacionados à economia aplicada. Esse aspecto corrobora as afirmações de Lisboa (2000) e Polanyi (1994) de que existe a crença de que o processo que engendrou a economia esteja fundamentado apenas nas leis econômicas, desconsiderando outras variáveis socioambientais.

Outro aspecto é a formação do economista cujos currículos seguem à própria tradição da ciência econômica, centradas em estudos do mainstream e que tradicionalmente excluem o meio ambiente como relevante para compreensão da dinâmica econômica. Contudo os resultados apontam que há uma 
interface, mesmo que ainda muito tênue, entre a pesquisa na área econômica no Brasil e as questões relacionadas ao meio ambiente. Isso pode ter várias origens:

- não apropriação do tema ao mainstream da economia;

- predominância da discussão sobre a intervenção do Estado em políticas macroeconômicas; a interveniência da matemática como forma método de racionalização dos problemas econômicos;

- incapacidade de lidar com a complexidade do tema, que sobrepõe a questão singular de um recurso e expande a proposição de integração na relação do homem com o meio natural;

- imprecisão da classificação de trabalhos pela próprio posicionamento generalista de muitas discussões que consolida quase metade do corpo docente a economia geral;

- falta de precisão dentro da subárea que trata da relação entre economia e meio ambiente, presente por termos não consolidados e controversos, como economia verde e cidades sustentáveis

- relação ideológica controversa dentro do próprio campo da ciência econômica, com observações diferentes sobre as expectativas da evolução desta interação entre o homem e o meio ambiente

Nesse diapasão, o distanciamento entre a teoria econômica e o meio ambiente diminui, mas de maneira controversa na área. A pesquisa na área ratifica essa tendência, mas os próprios teóricos preferem, muitas vezes, não considerar o problema ou não se aproximar interdisciplinarmente de outras áreas que poderiam dar mais consistência a essa discussão. A integração e interação entre economista e cientistas ambientais é necessária para articulação de produções científicas interdisciplinares, dentro das abordagens disciplinares de cada área.

\section{Referências}

ANDRADE, Daniel Caixeta. Valoração econômica ecológica: bases conceituais e metodológicas. São Paulo: Annablume, 2013.

BAUMOL, W. J.; OATES, W. E. The use of standards and prices for protection of the environment. The Swedish Journal of Economics, v. 73, n. 1, p. 42-54, mar. 1971.
BELL, John Fred. História do pensamento econômico. 2. ed. Rio de Janeiro: Zahar, 1976.

BRASIL. Ministério da Educação. Coordenação de Aperfeiçoamento de Pessoal de Nível Superior. Plano Nacional de Pós-Graduação - PNPG 2011-2020 / Coordenação de Pessoal de Nível Superior. Brasília, DF: CAPES, 2010. (2 v.).

Coordenação de Aperfeiçoamento de Pessoal de Nível Superior - CAPES. Documento de área 2013. Diretoria de Avaliação. Avaliação Trienal 2013. Disponível em: <http://www.capes.gov.br/images/stories/ download/avaliacaotrienal/Docs_de_area/Economia_doc_area_e_comiss\%C3\%A3o.pdf $>$ Acesso em: 02 abr. 2013.

GEORGESCU-ROEGEN, N. The entropy law and the economic process, Nueva York, Harvard: University Press, 1971.

HACKETT, Steven C. Environmental and natural resources economics. 3. ed. New York, United States: M.E.Sharpe, 2006.

HORKHEIMER, Max. Eclipse da razão. São Paulo: Centauro, 2002.

JEVONS, W. Stanley. A teoria da economia política. Tradução de Cláudia Laversveiler de Morais. São Paulo: Nova Cultural, 1996. (Série Os Economistas).

LISBOA, Armando de Melo. A crítica de Karl Polanyi à utopia do mercado. SOCIUS Working Papers, Lisboa, n. 2/2000, Instituto Superior de Economia e Gestão, Universidade Técnica de Lisboa, 2000.

MALTHUS, Thomas Robert. Princípios de economia política e considerações sobre sua aplicação prática. Tradução de Regis de Castro Andrade, Dinah de Abreu Azevedo e Antonio Alves Cury. São Paulo: Nova Cultural, 1996. (Série Os Economistas).

MARSHALL, Alfred. Princípios de economia, tratado introdutório. Tradução revista de Rômulo Almeida e Ottolmy Strauch. São Paulo: Nova Cultural, 1996. (Série Os Economistas).

MARX, Karl. O capital: crítica da economia política. São Paulo: Livraria Editora Ciências Humanas, 1996. (Livro 1, cap. IV).

MINISTÉRIO DA EDUCAÇÃO - MEC. Coordenação de Aperfeiçoamento de Pessoal de Nível Superior Capes. Contribuição da pós-graduação brasileira para o desenvolvimento sustentável. Capes na Rio+20. Brasília: Capes, 2012. 194 p.

MOTA, José Aroudo. O valor da natureza: economia e política dos recursos ambientais. Rio de Janeiro: Garamond, 2006.

MOTTA, Ronaldo Seroa. Economia ambiental. Rio de Janeiro: Editora FGV, 2007.

POLANYI, Karl. El sustento del hombre. Barcelona: Mondadori, 1994.

QUIVY, Raymond; CAMPENHOUDT, LucVan. Manual de investigação em ciências sociais. Lisboa: Gradiva, 1998.

ROMEIRO, A. R. Economia ou economia política da sustentabilidade. In: MAY, P.; LUSTOSA, M. C.; VINHA, V. (Org.). Economia do meio ambiente: teoria e prática. Rio de Janeiro: Editora Campus, 2003. p. 1-29. 
SOLOW, R. M. The economics of resources or the resources of economics. American Economic Review, v. 64, n. 2, p. 1-14. 1974.

SMITH, Adam. A riqueza das nações. Tradução de Paulo Henrique Ribeiro Sandroni. São Paulo: Abril Cultural, 1996. (Série Os Economistas).

STIGLITZ, J. E. Growth with Exhaustible Natural Resources. Review of Economic Studies, v. 42, p. 122-152. 1974.
WARD, B. e DUBOS, R. Only one earth: the care and maintenance of a small planet. Harmondsworth: Penguin Books Ltd, 1972.

WEBER, Max. A ética protestante e o espírito do capitalismo. São Paulo: Pioneira, 1996.

WEBER, Max. Economia e sociedade: fundamentos da sociologia compreensiva. Brasília: Unb, 1999. v. 1. 